\title{
Effect of fasting on insulin receptor-related receptor messenger ribonucleic acid in rat kidney
}

\author{
D Chrysis, B M Moats-Staats and L E Underwood
}

Department of Pediatrics, Division of Endocrinology, The University of North Carolina at Chapel Hill, Chapel Hill, North Carolina 27599, USA

(Requests for offprints should be addressed to L E Underwood, Pediatric Endocrinology, CB 7220509 Burnett-Womack Building, The University of North Carolina at Chapel Hill, Chapel Hill, North Carolina 27599-7220, USA)

\begin{abstract}
The insulin receptor-related receptor (IRR), a member of the insulin receptor tyrosine kinase family, has structural homology to the insulin receptor (IR) and the IGF-I receptor (IGF-IR). The ligand, gene regulation and biological function of the IRR are not known. Because mRNAs for both the IR and IGF-IR are increased by nutrient restriction, we used
\end{abstract}

\section{Introduction}

The insulin receptor family includes three members: The insulin receptor (IR), the type 1 insulin-like growth factor-I receptor (IGF-IR) and the insulin receptor-related receptor (IRR). These receptors show considerable similarity in structure and amino acid sequence, and each possesses a common disulfide-linked $(\alpha \beta)_{2}$ subunit structure (Shier \& Watt 1989). The genes encoding the three receptors are highly homologous, especially for the portion of the $\beta$-subunit that encodes tyrosine kinase activity (Shier \& Watt 1989). In contrast to the widespread expression of IR and IGF-IR mRNAs in rat, IRR mRNA expression is limited mainly to the renal cortex, stomach, thymus and brain (Mathi et al 1995, Bates et al 1997, Ozaki et al 1997, Tsujimoto et al. 1995, Shier \& Watt 1992, Kurachi et al. 1992), and is often colocalized in these tissues with the IR and IGF-IR.

The ligand for the IRR is unknown, and the receptor has been shown not to bind insulin, IGF-I, IGF-II, relaxin or nerve growth factor (NGF) (Jui et al. 1994, Zhang \& Roth. 1992). The IRR appears to have function, because IR/IRR chimeric receptors and IRR in neuroblastoma cells exhibit tyrosine kinase activity, increased thymidine incorporation and protein kinase activity (Zhang \& Roth 1992, Kovacina \& Roth 1995).

Fasting causes serum insulin and IGF-I to decrease, and reduces the abundance of IGF-I mRNA in many tissues, including kidney (Thissen et al. 1994, Lowe et al. 1989). Concurrently, the mRNAs for the receptors for these peptides are upregulated by fasting (Lowe et al. 1989, Kasuga et al. 1977). We speculated, therefore, that the structural homology and the colocalization of the IRR with the IGF-I and insulin receptors could be evidence that factors that regulate insulin, IGF-I and their receptors may also affect the expression of the
RNase protection assays to assess the effects of fasting $48 \mathrm{~h}$ on IRR mRNA in kidneys of rats. We compared the changes in IRR with those in IR and IGF-IR mRNAs. We observed a significant increase in steady state levels of IRR (ratio of IRR mRNA to $\beta$-actin in fed $v s$ fasted animals, $0.59 \pm 0.1$ and $1.25 \pm 0.14$ respectively, $P<0.01$ ), suggesting that the ligand for IRR also might be regulated by nutrients.

IRR mRNA. Therefore, we assessed whether fasting would increase the level of mRNA for the IRR in rat kidney.

\section{Materials and Methods}

\section{Experimental design}

Five-week old male Sprague-Dawley rats $(n=12$, Charles River, Wilmington, MA, USA), weighing 140-160g, were housed in our animal care facility in 12-h light, 12-h dark cycles. The study protocol was approved by our Institutional Animal Care and Use Committee. Animals were divided into two groups of 6 and were either fasted for $48 \mathrm{~h}$, or fed $a d$ libitum. Each animal had free access to water. Body weight was measured daily. At the end of the experiment, blood was collected by cardiac puncture under ether anesthesia, and serum was stored at $-20^{\circ} \mathrm{C}$. The kidneys were removed quickly, frozen in liquid nitrogen, minced on dry ice, and stored at $-70^{\circ} \mathrm{C}$.

\section{Measurement of IGF-I in serum}

IGF-I serum concentrations were measured by RIA after removal of IGF binding proteins using ODC-silica cartridge chromatography (C-18 Sep-Pak; Waters, Milford, MA, USA) (Davenport et al. 1988).

\section{Kidney RNA extraction and hybridization probes}

Total RNA was isolated from each kidney (Chomezynski \& Sacchi 1987), and poly(A)+-enriched RNA was obtained by one passage through an oligo(dT)-cellulose column. A rat IRR riboprobe encoding exon 3 was generously provided by Richard A Roth (Stanford University, School of Medicine, Palo Alto, CA, USA) (Reinhardt et al.1993). Using this probe, 
a RNase protection assay gave a $285 \mathrm{nt}$ protected fragment, consistent with protection of exon 3 of the IRR mRNA. A rat IR riboprobe was synthesized from a $2.3 \mathrm{~kb}$ cDNA (kindly provided by Barry J Goldstein, Thomas Jefferson University, Medical College, Philadelphia, PA, USA) cloned into the pBluescript $\mathrm{SK}(-)$ plasmid. The cDNA fragment derived from digestion with $\mathrm{Bgl} 2$ was 372 nt long. The rat IGF-I receptor probe was amplified with PCR using primers specific for the IGF-IR cDNA including 15 bases of the 5'-untranslated region and the sequence for the first 53 amino acids of the $\alpha$ subunit (Werner et al. 1989), and gives a protected fragment of $265 \mathrm{nt}$ in the RNase protection assay. A consensus sequence of T3 or T7 RNA polymerase promoters was included in the primers to generate sense or antisense transcripts. Labeled IGF-IR, IR and IRR antisense RNAs were synthesized with T3 or T7 polymerase (Promega Corp., Madison, WI, USA) using Biotin14-CTP (Ambion Corp., Austin, TX, USA). A rat $\beta$-actin riboprobe, giving a protected band of 126 bases, was obtained from Ambion Corp. (Austin, TX, USA) and labeled in a manner similar to the other probes except that a 1:2 dilution of biotin-14-CTP was used to reduce the $\beta$-actin signal.

\section{RNase protection assay}

Four micrograms of poly $(\mathrm{A})^{+}$-enriched RNA derived from each kidney sample for the detection of IR and IGF-IR, or $8 \mu \mathrm{g}$ for detection of the IRR, were hybridized overnight at $45^{\circ} \mathrm{C}$ with $2.5 \mathrm{fmol}$ of labeled IR, IGF-IR or IRR antisense RNAs, and 3.5 fmol of $\beta$-actin antisense RNA. Hybridization of IR and IGF-IR to their respective probes was accomplished simultaneously in the same tube. After hybridization, samples were treated with A and T1 RNases (Ambion, Austin, TX, USA) at $37^{\circ} \mathrm{C}$ for $30 \mathrm{~min}$. Protected fragments were separated on a $5 \%$ acrylamide $/ 8 \mathrm{M}$ urea gel and transferred to nylon membranes by electroblotting. Pilot experiments using yeast RNA in amounts equal to experimental samples confirmed that the concentration of probes was in molar excess and the digestion conditions were complete for non-specific hybridization. For washing and for detecting the signal, protocols recommended by the manufacturer (Ambion) were followed. Each blot was exposed repeatedly (3-6 times) for different periods of time with Biomax MR film, (Kodak, Rochester, NY, USA) and each band was quantified densitometrically using the Image-Pro Plus system (Media Cybernetics, Silver Spring, MD, USA). Because the $\beta$-actin mRNA is quite abundant, its signal was quantified from autographs with shorter exposure times. Each band of interest was normalized to $\beta$-actin and expressed as the ratio of the band of interest to the $\beta$-actin band from the same RNA preparation.

\section{Statistics}

All values are presented as mean \pm S.E.M. Student's $t$ test was used to determine the significance of differences between groups. $P$ values less than 0.05 were considered significant.
Table 1 Changes of body weight $(\mathrm{g})$ and serum IGF-I in rats fasted for $48 \mathrm{~h}$ and in ad libitum fed rats

\begin{tabular}{llll} 
& Prefast & Day 2 & $\begin{array}{l}\text { Serum IGF-I } \\
(\mathrm{ng} / \mathrm{ml})\end{array}$ \\
\hline Fasted & $186.5 \pm 6.3$ & $167.0 \pm 4.7^{\mathrm{a}}$ & $881 \pm 45^{\mathrm{a}}$ \\
Controls & $189.5 \pm 5.1$ & $210.7 \pm 8.2$ & $1934 \pm 95$ \\
\hline
\end{tabular}

${ }^{a} P<0.001$ vs control group.

\section{Results}

\section{Effects of fasting on growth and serum IGF-I}

Fasting for $48 \mathrm{~h}$ decreased body weight by $10 \%$ from pre-fast values whereas weight in the control group increased by $11 \%$ (Table 1). As expected, serum IGF-I concentrations in fasted rats were $46 \%$ of control fed rats $(P<0.001$, Table 1$)$.

\section{Alteration in abundance of IR, IGF-IR and IRR mRNAs in kidneys from fasted and fed rats}

RNase protection assays revealed the presence of the transcripts of interest of the predicted sizes (Figs 1 and 2). There was no difference in the mean values for $\beta$-actin transcripts from fasted and control fed animal $(485 \pm 20$ and $450 \pm 18$ arbitrary optical density units, respectively, $P>0.05$ ). IGF-IR transcripts were significantly increased in fasted compared to fed animals (ratio of IGF-IR to $\beta$-actin; $7.1 \pm 0.44$ in fasted and $1.98 \pm 0.24$ in fed; $P<0.0001$ ), (Fig. 1). The same increase was observed for the IR transcripts $(2.36 \pm 0.88$ in fasted and $0.65 \pm 0.54$ in fed; $P<0.0001$ ), (Fig. 1). IRR transcripts were also significantly increased in fasted compared to fed animals $(1.25 \pm 0.14$ and $0.59 \pm 0.1$, respectively;

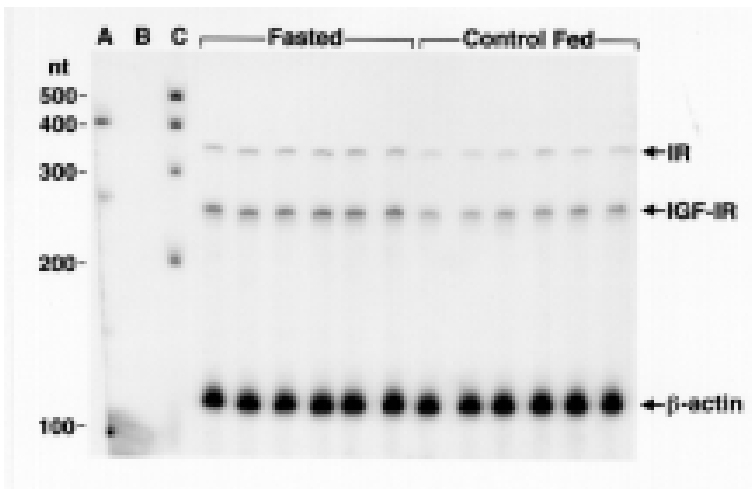

Figure 1 RNase protection assay of kidney IR and IGF-IR mRNAs in fasted and control-fed rats. Lane A, undigested riboprobes for IR (432 nt), IGF-IR (285 nt) and $\beta$-actin (165 nt). Lane B, yeast RNA and probes with RNase, Lane C, RNA ladder. The remaining lanes contain four micrograms of kidney Poly $(A)+$ RNA from each rat of the two groups hybridized with IR, IGF-IR and $\beta$-actin riboprobes. 


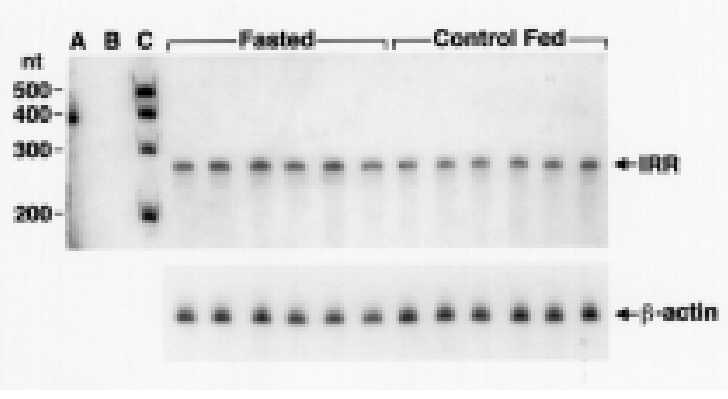

Figure 2 RNase protection assay of kidney IRR mRNA in fasted and control-fed rat. Lane A, undigested riboprobe for IRR (380 nt), Lane B, yeast RNA and probe with RNase, Lane $C$, RNA Ladder. Lanes from fasted and control rats contain eight micrograms of $\operatorname{Poly}(A)+R N A$ from each rat hybridized with IRR and $\beta$-actin. The figure with $\beta$-actin transcript is from the same blot as that for IRR but was exposed for a short period of time for the $\beta$-actin signal.

$P<0.01$ ), (Fig. 2). The above results were confirmed with three different RNase protection assays from the same animals and RNA preparations.

\section{Discussion}

Our results indicate that fasting causes increased expression of the IR, IGF-IR and IRR mRNAs in rat kidneys. A similar increase in IGF-IR mRNA in kidneys of fasted rats has been reported (Lowe et al. 1989), and increased IR mRNA with fasting has been described in liver, muscle, adipose tissue of rats and in kidneys of chickens (Knott et al. 1992). Although the IRR mRNA increment was less striking, it was statistically significant and reproducible in three separate experiments.

Expression of the IR and IGF-IR is related inversely to their ligand concentrations, such that increased concentrations of insulin and IGF-I are accompanied by decreased expression of their respective receptor genes (Knott et al. 1992, Hernandez-Sanchez et al. 1997). Conversely fasting causes serum insulin and IGF-I peptide and tissue IGF-I mRNAs to decline. It seems likely therefore, that the increased expression of IR and IGF-I receptor mRNAs during fasting is related to reduction of their ligands. The structural homology among the IRR, IR and IGF-IR predict that the IRR ligand has similarities with insulin and IGF-I. The up-regulation of the IRR mRNA during fasting may indicate that the ligand for this receptor also is down-regulated by this dietary manipulation.

Increased expression of IRR mRNA during fasting does not indicate necessarily that IRR binding sites are increased. However, in tissues with increased expression of IR and IGF-I mRNAs, increased numbers of receptors are observed (Lowe et al. 1989, Knott et al. 1992, Hernandez-Sanchez et al. 1997). Each of the three receptors in this family are colocalized in the renal cortex, making possible the formation of hybrid receptors, and their up-regulation during fasting may modulate the actions of their ligands.

\section{Acknowledgements}

This work was supported by NIH Research Grant HD 26871 and an Endocrine Fellowship Grant from the Eli Lilly Co, Indianapolis, IN, USA.

\section{References}

Bates CM, Merenmiedes JM, Kelly-Spratt KS \& Parada LF 1997 Insulin receptor-related receptor expression in non-A intercalated cells in the kidney. Kidney International 52 674-681.

Chomczynski P \& Sacchi N 1987 Single-step method of RNA isolation by acid guanidinium thiocyanate-phenol-chloroform extraction. Annals of Biochemistry 162 156-159.

Davenport ML, Svoboda ME, Koerber KL, Van Wyk JJ, Clemmons DR \& Underwood LE 1988 Serum concentrations of insulin-like growth factor II are not changed by short-term fasting and refeeding. Journal of Clinical Endocrinology and Metabolism 67 1231-1236.

Hernandez-Sanchez C, Werner H, Roberts Jr CT, Woo EJ, Hum DW, Rosenthal SM \& LeRoith D 1997 Differential regulation of insulin-like growth factor-I (IGF-I) receptor gene expression by IGF-I and basic fibroblastic growth factor. Journal of Biological Chemistry 272 4663-4670.

Jui H-Y, Suzuki Y, Accili D \&Taylor S I 1994 Expression of a cDNA encoding the human insulin receptor-related receptor. Journal of Biological Chemistry $26922446-22452$.

Kasuga M, Akanuma Y, Iwamoto Y \& Kosaka K 1977 Effects of fasting and refeeding on insulin receptors and glucose metabolism in rat adipocytes. Endocrinology 100 1384-1390.

Knott RM, Trayhurn P \& Hesketh JE 1992 Changes in insulin receptor mRNA levels in skeletal muscle and brown adipose tissue of weanling rats during fasting and refeeding. British Journal of Nutrition 68 583-592.

Kovacina KS \& Roth RA 1995 Characterization of the endogenous insulin receptor-related receptor in neuroblastomas. Journal of Biological Chemistry 270 1881-1887.

Kurachi H, Jobo K, Ohta M, Kawasaki T \& Itoh N 1992 A new member of the insulin receptor family, insulin receptor-related receptor, is expressed preferentially in the kidney. Biochemical and Biophysical Research Communications 187 934-939.

Lowe Jr WL, Adamo M, Werner H, Roberts Jr CT \& LeRoith D 1989 Regulation by fasting of rat insulin-like growth factor I and its receptor: effects on gene expression and binding. Journal of Clinical Investigation 84 619-626.

Mathi SK, Chan J \& Watt VM 1995 Insulin receptor-related receptor messenger ribonucleic acid: quantitative distribution and localization to subpopulations of epithelial cells in stomach and kidney. Endocrinology 136 4125-4132.

Ozaki K, Takada N, Tsujimoto K, Tsuji N, Kawamura T, Muso E, Ohta M \& Itoh N 1997 Localization of the insulin receptor-related receptor in the rat kidney. Kidney International 52 694-698.

Reinhardt RR, Chin E, Zhang B, Roth RA \& Bondy CA 1993 Insulin receptor-related receptor messenger ribonucleic acid is focally 
expressed in sympathetic and sensory neurons and renal distal tubule cells. Endocrinology 133 3-10.

Shier P \& Watt VM 1989 Primary structure of a putative receptor for a ligand of the insulin family. Journal of Biological Chemistry 264 14605-14608.

Shier P \& Watt VM 1992 Tissue-specific expression of the rat insulin receptor-related receptor gene. Molecular Endocrinology 16 723728.

Thissen JP, Ketelslegers JM \& Underwood LE 1994 Nutritional regulation of the insulin-like growth factors. Endocrine Reviews 15 80-101.
Tsujimoto K, Tsuji N, Ozaki K, Ohta M \& Itoh N 1995 Insulin receptor-related receptor messenger ribonucleic acid in the stomach is focally expressed in the enterochromaffin-like cells. Endocrinology 136 558-561.

Werner H, Woloschak M, Adamo M, Shen-Orr Z, Roberts Jr CT \& LeRoith D 1989 Developmental regulation of the rat insulin-like growth factor I receptor gene. Proceedings of the National Academy of Sciences of the USA 86 7451-7455.

Zhang B \& Roth RA 1992 The insulin receptor-related receptor. Tissue expression, ligand binding specificity, and signaling capabilities. Journal of Biological Chemistry 267 18320- 18328. 